\title{
POCKETS OF OPEN CELLS AND DRIZZLE IN MARINE STRATOCUMULUS
}

by Bjorn Stevens, Gabor Vali, Kimberly Comstock, Robert Wood, Margreet C. van Zanten, Philip H. Austin, Christopher S. Bretherton, and Donald H. Lenschow

The relationship between drizzle and cloud morphology, as manifest in transitions to spatially compact regions of open cellular convection, is studied using data collected from recent field studies over the northeast and southeast Pacific.

A curious feature of the cloud climatology over regions of the globe where low-lying marine stratiform clouds predominate is the appearance of pockets of seemingly cloud-free air embedded in an otherwise homogeneous cloud field. The irregularities in the cloud field as seen in the visible satellite imagery in the left and upper panels of Fig.1 are an example of such features. Here two elongated regions of very low

AFFILIATIONS: STEVENS AND VAN ZANTEN-Department of Atmospheric Sciences, University of California, Los Angeles, Los Angeles, California; VALI-Department of Atmospheric Science, University of Wyoming, Laramie, Wyoming; COMSTOCK, WOOD, AND BRETHERTON-Department of Atmospheric Sciences, University of Washington, Seattle, Washington; VAN ZANTENInstitute of Marine and Atmospheric Research Utrecht, Utrecht University, Utrecht, Netherlands; Austin-Atmospheric Sciences Programme, University of British Columbia, Vancouver, British Columbia, Canada; LeNSCHOW-National Center for Atmospheric Research, Boulder, Colorado

CORRESPONDING AUTHOR: Bjorn Stevens, Department of Atmospheric and Oceanic Sciences, Box 951565, University of California, Los Angeles, Los Angeles, CA 90095-1564

E-mail: bstevens@atmos.ucla.edu

doi:|0.1 I75/BAMS-86-I-5 I

In final form 30 June 2004

(O2005 American Meteorological Society reflectivity stripe the southern portion of the cloud field, with more irregular pockets evident in the eastward extension of these low-reflectivity bands. Because factors that regulate the reflectivity of low clouds can critically affect the climate system as a whole (e.g., Randall et al. 1984; Ma et al. 1996), features such as these are not simply curious. To the extent they provide clues into processes that regulate cloudiness on larger scales, hence climate, they may be important as well.

Upon closer examination such low reflectivity pockets or bands are rarely completely clear; instead they evince an underlying patterning reminiscent of open cellular convection (Agee 1984). The extent of this patterning varies among cases and, for any particular case, with time.

In Fig. 1, hints of cellular patterning are most evident at earlier times, and in the westward extension of the bands. To highlight the particularly curious tendency of these spatially compact, cellular-patterned, low-reflectivity regions to be embedded in otherwise stratiform cloud fields, we hereafter refer to them as pockets of open cells (POCs). It remains to be seen whether such a distinction can be physically, rather than methodologically, justified.

By looking at $\Delta T_{B}$, the difference between the 11- and 4- $\mu \mathrm{m}$ brightness temperature, POCs can also be detected in the nighttime satellite imagery. This is 


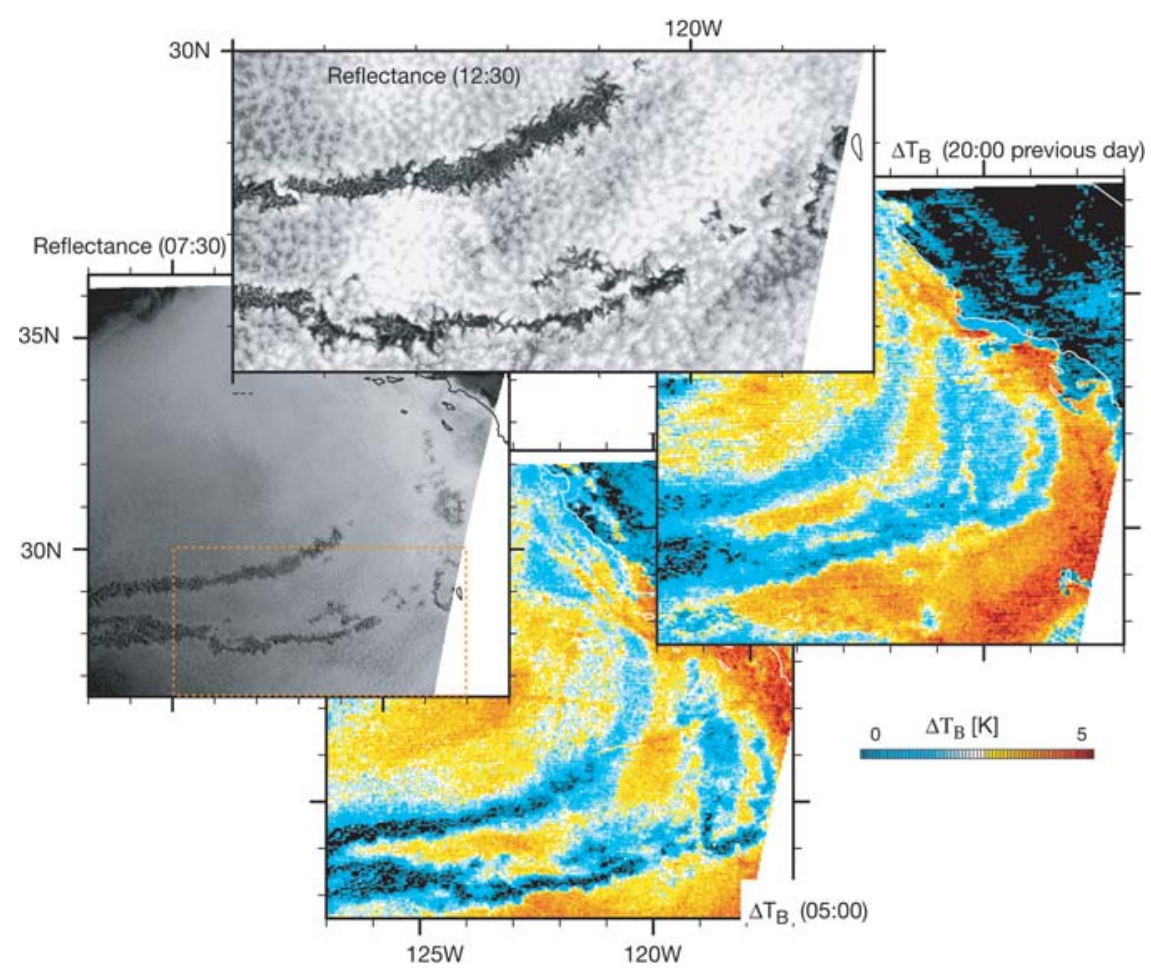

FIG I. Temporal sequence of GOES-10 images spanning I6.5 h over the northeast Pacific on $27 \mathrm{Jul} 200 \mathrm{I}$. The color images are differences between channels $4(3.9 \mu \mathrm{m})$ and 2 ( I I $\mu \mathrm{m})$ of GOES, while the grayscale image is cloud albedo as measured by channel one radiances. The visible image has a pixel size of I km, in contrast to the 4-km pixel of the infrared imagery. The domain of the upper panel is shown by the orange dashed box in the left panel. cent East Pacific Investigation of Climate (EPIC) field study (Bretherton et al. 2004) a boundary between a region of open and closed cellular convection advected over the National Oceanic and Atmospheric Administration (NOAA) Research Vessel the Ronald H. Brown (see Fig. 2). Here the microphysical structure of the cloud fields is investigated with the help of an upward-pointing cloud radar (Moran et al. 1998), whose measurements of reflectivity at $35 \mathrm{GHz}$ are contoured in time-height space at the bottom of Fig. 2 . The analysis suggests that when the region of open cellular convection is overhead the radar reflectivity field has a more cellular structure, with frequent periods of large reflectivities (a proxy for drizzle, e.g., Vali et al. 1998) extending to the surface. In the region to the

shown in the right and bottom panels of Fig. 1, which show that these POCs are coherent, long lived (the images span $16.5 \mathrm{~h}$ ), and embedded in regions of relatively small values of $\Delta T_{B}$. The longevity and coherence of POCs has attracted the attention of satellite meteorologists, with observational examples of POC-like features dating to the beginning of the satellite record (e.g., Krueger and Fritz 1961; Davies and Garay 2003; Garay et al. 2004). Low values of $\Delta T_{B}$ can be accounted for by a reduction in the cloud optical depth from values of 15 to unity (which is not consistent with the earlymorning visible imagery), or by changes in the effective radius from 6 to $12 \mu \mathrm{m}$ for a cloud with a fixed optical depth of 15 (e.g., Fig. 1 of Perez et al. 2000). Thus, we conclude that the POCs are favored in regions of the cloud field where the cloud droplets are larger and thus have a greater propensity to form precipitation. Such a finding is consistent with previous observations (e.g., Han et al. 1995; Gerber 1996), as well as the strong correlation between measured drizzle and $\Delta T_{B}$ found by van Zanten et al. (2004).

Longevity and drizzle also seem to be characteristic not only of POCs, but of broader regions of open cellular convection as well. For instance, during the re- south (sampled by the ship after 0900 local time) radar reflectivities are considerably smaller and the cloud field as measured by GOES appears more homogeneous. Although this is difficult to establish from the satellite imagery alone, in part because of the confounding effects of the diurnal cycle, close examination of the 1200 LT imagery is indicative of a more closed-cellular (brighter centers) cloud pattern over the ship, a view that is also consistent with observer records and shipboard photography (not shown). While not definitive, the imagery supports the idea that regions of open cellular convection are characterized by cloud fields more conducive to precipitation, and that the boundaries between the different modes of convection are coherent over long periods of time. The argument that regions of precipitation tend to be preferentially associated with regions of more open cellular convection is, in retrospect, consistent with in situ measurements and satellite images from earlier field studies (e.g., Fig. 1 of Austin et al. 1995), as well as the tendency for such regions to be more favorable for the formation of ship tracks (Scorer 1987).

To further evaluate the relationship between POCs and precipitation we analyze data from the second re- 
search flight (RF02) of the Dynamics and Chemistry of Marine Stratocumulus (DYCOM-II) field study (Stevens et al. 2003b), which serendipitously sampled across a POC. Figure 3 shows the morning visible satellite imagery and reflectivity from a downwardlooking airborne cloud radar. In the nighttime satellite imagery the "tilde"-shaped POC, which is isolated in the upper-left panel of Fig. 3 and is the focus of this analysis, appears to break away from the broader region of open cellular convection to the west, thus reinforcing the relationships discussed above. Its subsequent propagation is consistent with it being advected by the mean boundary layer wind, and it remains coherent for at least $10 \mathrm{~h}$. Similar to what was found for the case study from EPIC, reflectivity data from the cloud radar show that the POC is composed of mesoscale cells whose walls are loci of intensified convection, with locally higher cloud tops, and radar backscatter (i.e., drizzle) extending to the sea surface. Cell interiors have locally lower cloud tops and even regions of complete clearing. Because the lidar, unlike the radar, is sensitive to even trace amounts of cloud, the clearings in Fig. 3 are best identified by regions where the lidar pulse penetrates to the surface. As was evident in the EPIC data, more overcast regions in the satellite imagery are associated with more uniform clouds with little or no precipitation. This provides further evidence that regions of open cellular convection are coincident with precipitating regions of the flow.

In situ measurements allow us to be more quantitative. In Fig. 4 we show data from two 30-min legs flown near sunrise, first at $100 \mathrm{~m}$ and then at $1100 \mathrm{~m}$. For orientation, our estimate of the airmass sampled by the flight legs is overlaid on the $\Delta T_{B}$ field as derived from Geostationary Operational Environmental Satellites (GOES). Because the POC appears to translate with the mean boundary layer wind this estimate is derived by advecting the aircraft position following the procedure outlined in Stevens et al. (2003a). The region of the POC is still evident in the tilde-shaped envelope of near zero values of $\Delta T_{B}$, which is clearly bisected by both tracks. As in Fig. 1 the POCs in the vicinity of RF02 are embedded in a broader cloud field characterized by relatively small values of $\Delta T_{B}$, or large droplets. Indeed, droplet concentrations during RF02 were among the lowest of all flights, averaging about $60 \mathrm{~cm}^{-3}$ (van Zanten et al. 2004). Data from both flight periods are shown as time series in the figure: the northern, near-surface, flight leg was flown in a clockwise direction and bisected the POC during the first $900 \mathrm{~s}$ of the time series (shown in upper panel); the southern leg was flown in a counterclockwise fashion 300-400 m above cloud top, crossing over the POC near the middle of the leg. For both flight legs the time period during which the aircraft bisected the POC is highlighted, both on the flight track and by the red arrow within the time series panels. The liquid water content $q_{l}$ from the northern (surface) track and the reflectivity 


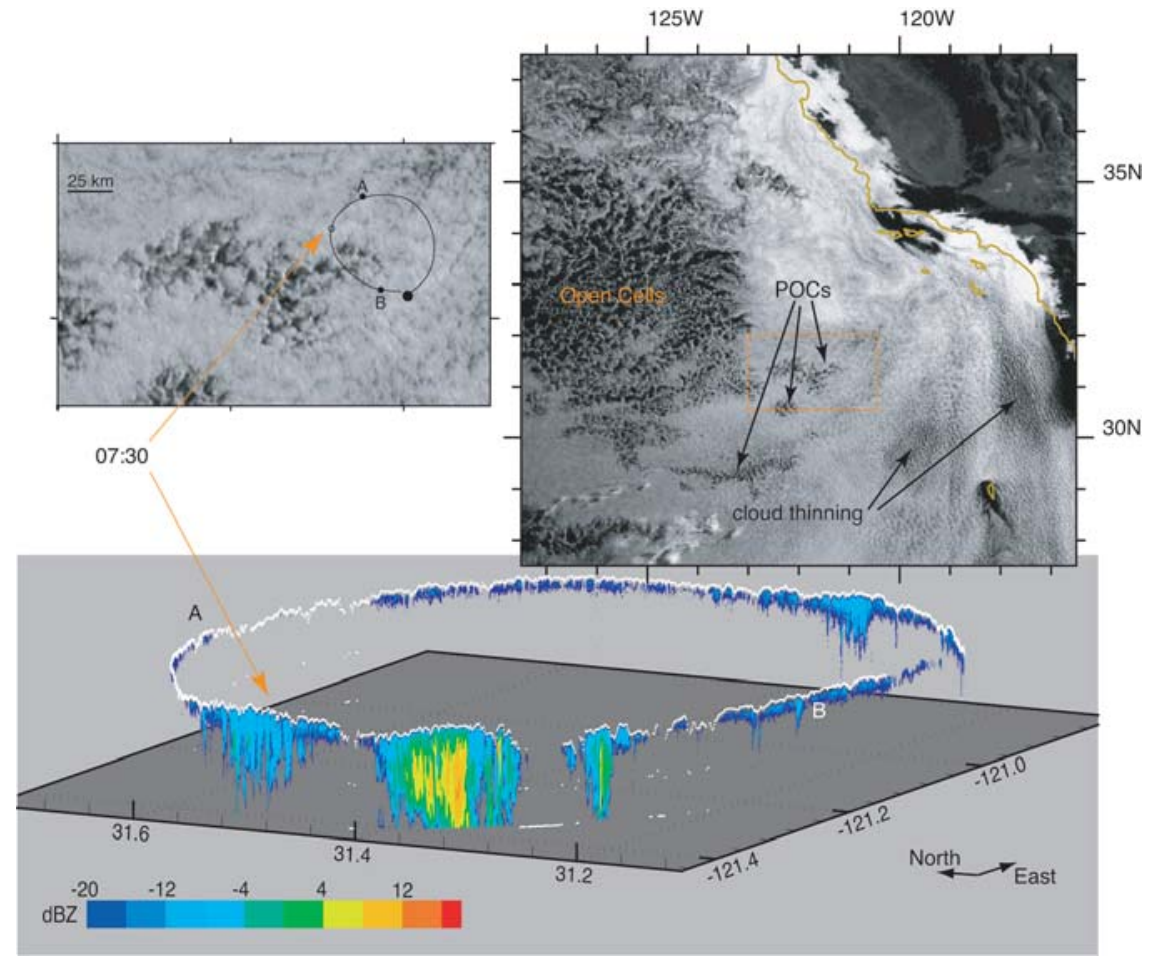

FIg 3. (top right) Channel I $(0.6 \mu \mathrm{m})$ reflectance over the northeast Pacific from GOES-IO at 0730 LT (I430 UTC) for I I Jul 2002. (top left) Zoomed image of reflectance field from boxed region in regional image; overlaid on this image is a flight segment from RF02 that spans the time of the overpass and from which radar and lidar data is presented in top left panel. The zoomed image highlights a tilde-shaped POC boxed in the image. (bottom) Time-height radar reflectivities filled, with cloud top height as estimated by downward-looking lidar shown by white line. Regions where lidar detects no cloud are shown by a lidar trace at the surface. The time for which the satellite image is valid is indicated on the flight tracks.

from the southern (above cloud) track reinforce the idea that POCs delineate regions of locally enhanced precipitation. Based on locally tailored reflectivity-rainrate relationships (an extensive discussion of which is provided in van Zanten et al. 2004), and in situ data taken along the surface leg, we estimate mean surface precipitation rate from the radar to be on the order of $1 \mathrm{~cm} \mathrm{day}^{-1}$ within the precipitating cell walls of the POC. These are the largest values measured in stratocumulus during DYCOMS-II and more than twice the surface evaporation rate. Cloud-base rain rates are twoto threefold larger yet. Without replenishment, precipitation rates of this magnitude would deplete the cloud of all its liquid water in tens of minutes. The persistence, and coherence, of these vigorously precipitating regions suggest that the open cells are relatively stable-flow configurations that organize to maintain the moisture supply to the precipitating cell boundaries. Circulations capable of such transport are consistent with the observation that regions of enhanced radar reflectivity tend to have locally elevated cloud tops.

The cellular structure of the POC is manifest in the in situ near-surface measurements of the northern flight leg. Here the quasiperiodic regions of precipitation are associated with sharp increases in the total water mixing ratio, and reduced values of the temperature-cool but moist pools driven by the evaporation of precipitation in the subcloud layer (cf. Barnes and Garstang 1982; Jensen et al. 2000). Unlike the cold pools of deep precipitating convection that tend to be dry and cool and hence are characterized by large depressions of $\theta_{e}$, moisture enhancement in the precipitating regions we sample more than offsets the temperature perturbations, that is, these are regions of slightly elevated $\theta_{e}$. The mechanism for generating $\theta_{e}$ perturbations in the subcloud layer remains something of a puzzle, but we note that regions of elevated $\theta_{e}$ in association with precipitation rates commensurate with what we measure are also evident in the analysis presented by Barnes and Garstang (1982). The variability in the thermodynamic structure in the vicinity of the POCs is in marked contrast to the flow far from the POC, where the boundary layer thermodynamic structure is more uniform, and there is no evidence of surface precipitation. Although it is difficult to discern the detailed dynamics of the circulations in the vicinity of the cells from these data, the emergence of cells supports previous theoretical work (Bjerknes 1938; Stevens et al. 1998) that argues precipitation from initially stratiform clouds drives a more diabatic, cumulus-like circulation, characterized by narrower regions of convective ascent and broader regions of stabilized descent.

POCs tend to occur within cloud layers with large mean droplet radius and small droplet concentration, suggestive of a low-aerosol air mass. However, the specific location of POCs may also reflect other environ- 
mental factors. One possible factor is hinted at by the counterintuitive tendency for the boundary layer to be moister within the vicinity of the POC-in the absence of other processes drizzle would be expected to dry the boundary layer. Might the observed moistening reflect the tendency for the air directly above the POC (as measured by the above cloud track in the lower panels) to also be more humid? To the extent the moist layer sampled above the cloud in the vicinity of the POC actually impinges on the cloud layer one would expect a reduced rate of entrainment drying - in other words, a relative moistening of the PBL- which would tend to lower cloud base and favor precipitation formation. This may explain why the POC formed in the first place and why it is more localized than the region of large cloud droplet sizes seen in Fig. 4. Such an explanation is consistent with more global correlations evident among other DYCOMS-II flights: the average specific humidity just above the boundary layer (as measured by all cloud-top penetrations) on the three flights with the least precipitation was $2.2 \mathrm{~g} \mathrm{~kg}^{-1} \mathrm{com}$ pared to a value of $4.6 \mathrm{~g} \mathrm{~kg}^{-1}$ on the flights with the most precipitation. Similar correlations have been noted in the past field studies (Yuter et al. 2000), and are also apparent in the EPIC data. That said, it is difficult to raise these arguments above the level of suggestion. Data from aircraft soundings show evidence of the moist layer extending to the cloud top in the region of the POC; however, these data also show evidence of directional shear, which could serve as a basis for disrupting the vertical continuity in the moisture field above cloud top. For this reason, and because the sounding data are sparse, it is difficult to definitively establish that the features $300-400 \mathrm{~m}$ above the boundary layer extend down to cloud top. In addition, such presumed moistening effects could in part be offset by larger entrainment velocities in association with the
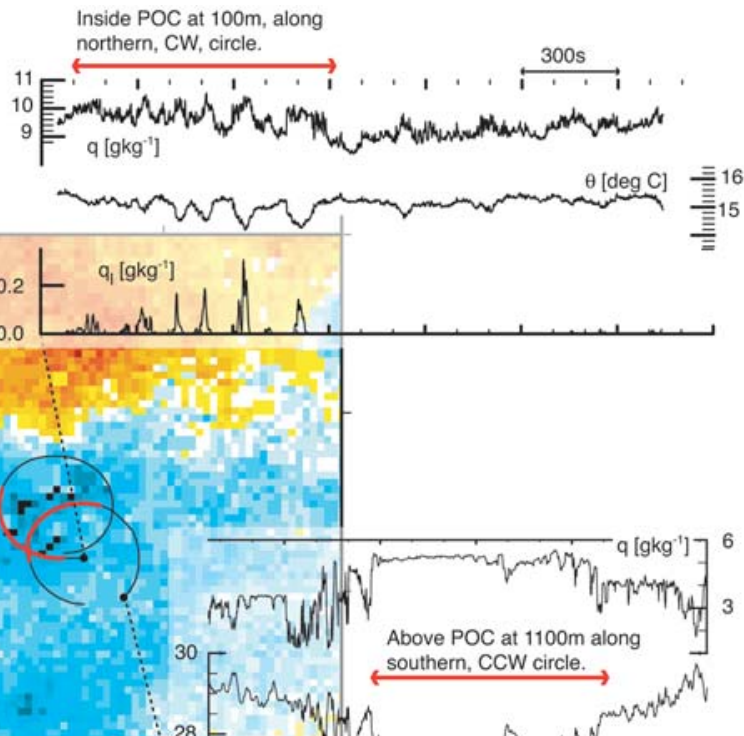

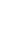

FIG 4. (left) Contours of $\Delta T_{b}$ from GOES-10 illustrating region of tilde-shaped POC, wight tracks valid at time of snapshot superimposed. (upper right) Time (from top to bottom) water vapor mixing ratio $(q)$ as measured by a nor $\alpha$ -

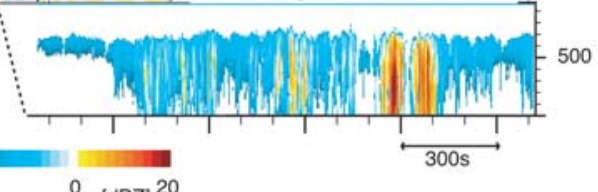

$-20$

$[\mathrm{dBZ}]^{20}$ 
gimes depending, for instance, upon the propensity of precipitation to form. In this respect our data provide empirical support for the idea that by modulating precipitation formation, perturbations in the atmospheric aerosol can affect patterns of cloudiness (e.g., Albrecht 1989; Rosenfield 2000; Lohmann and Lesins 2002). Although it may well turn out that the dynamics of POCs are not substantially different from broader regions of open cellular convection, their spatially compact nature make them well suited to comparisons with the surrounding, or background flow. As such they can provide a natural laboratory for investigating the interactions among cloud dynamics, precipitation, and properties of the atmospheric aerosol.

In summary, data from two recent field experiments in the northeast and southeast Pacific stratocumulus regions suggest that coherent, long-lived regions of open cellular convection are coupled to the development of precipitation. These findings are consistent with theoretical work that suggests that the transition to more strongly precipitating flows should induce such a cloud transition. Future experimental work that targets such features may greatly advance our understanding of the relationship between precipitation and cloudiness, one of the key uncertainties in relating perturbations of the atmospheric aerosol to changes in climate.

ACKNOWLEDGMENTS. This research was supported by the NSF through Grants ATM-0097053, ATM-0094956, ATM-0082384, and its support of the National Center for Atmospheric Research, as well through funding by NSERC/ CFCAS, ONR (through the EPSCoR program, NASA Grants NAGS5-10624, NAG 5-12559). The contributions of MVC were supported by the Stichting voor Fundamenteel Onderzoek der Materie (FOM), which is financially supported by the Nederlandse Organisatie voor Wetenschappelijk Onderzoek (NWO), and those of KC by an NDSEG fellowship. The authors wish to thank Christopher Fairall, Taneil Uttal, and Duane Hazen of NOAA ETL, and the staff and crew of the NOAA RHB for their assistance in collecting and interpreting EPIC data, as well as the scientists and staff of the Research Aviation Facility of NCAR in support of DYCOMS-II. Conversations and many insights collegially shared by Mike Garay, Melanie Wetzel, and Sandra Yuter are also gratefully acknowledged. Scott Loehrer and the Joint Office for Scientific Support (JOSS) are thanked for their help with the GOES imagery, as well as the reviewers for comments which considerably improved the presentation of this work. We would like to give special thanks to Bruce Albrecht, whose group it turns out has been working on a careful study of POC-like features (which they call rifts), for his careful and critical evaluation of our ideas; his attention to the details of our arguments has challenged and im- proved our understanding, substantially improving the final manuscript.

\section{REFERENCES}

Agee, E. M., 1984: Observations from space and thermal convection: A historical perspective. Bull. Amer. Meteor. Soc., 65, 938-949.

Albrecht, B. A., 1989: Aerosols, cloud microphysics and fractional cloudiness. Science, 245, 1227-1230

Austin, P., Y. Wang, R. Pincus, and V. Kujala, 1995: Precipitation in stratocumulus clouds: Observational and modeling results. J. Atmos. Sci., 52, 2329-2352.

Barnes, G. M., and M. Garstang, 1982: Subcloud layer energetics of precipitating convection. Mon. Wea. Rev., 110, 102-117.

Bjerknes, J., 1938: Saturated-adiabatic ascent of air through dry-adiabatically descending environment. Quart. J. Roy. Meteor. Soc., 64, 325-330.

Bretherton, C. S., and Coauthors, 2004: The EPIC 2001 stratocumulus study. Bull. Amer. Meteor. Soc., 85, 967-977.

Davies, R., and M. Garay, 2003: Actinoform clouds of the South Pacific: Self-organization in the marine boundary layer. Proc. Seventh Int. Conf. on Southern Hemisphere Meteorology and Oceanography, Wellington, New Zealand, Amer. Meteor. Soc., 136137.

Garay, M. J., R. Davies, C. Averill, and J. A. Westphal, 2004: Actinoform clouds: Overlooked examples of cloud self-organization at the mesoscale. Bull. Amer. Meteor. Soc., 85, 1585-1594.

Gerber, H., 1996: Microphysics of marine stratocumulus clouds with two drizzle modes. J. Atmos. Sci., 53, 1649-1662.

Han, Q., R. Welch, J. Chou, W. Rossow, and A. White, 1995: Validation of satellite retrievals of cloud microphysics and liquid water path using observations from FIRE. J. Atmos. Sci., 52, 4183-4195.

Jensen, J. B., S. Lee, P. B. Krummel, J. Katzfey, and D. Gogoasa, 2000: Precipitation in marine cumulus and stratocumulus: Part I: Thermodynamic and dynamic observations of closed cell circulations and cumulus bands. Atmos. Res., 54, 117-155.

Krueger, A. F., and S. Fritz, 1961: Cellular cloud patterns revealed by TIROS I. Tellus, 13, 1-7.

Lohmann, U., and G. Lesins, 2002: Stronger constraints on the anthropogenic indirect aerosol effect. Science, 298, 1012-1016.

Ma, C.-C., C. R. Mechoso, A. W. Robertson, and A. Arakawa, 1996: Peruvian stratus clouds and the tropical Pacific circulation: A coupled oceanatmosphere GCM study. J. Climate, 9, 1635-1645. 
Moran, K. P., B. E. Martner, M. J. Post, R. A. Kropfli, D. C. Welsh, and K. B. Widener, 1998: An unattended cloud-profiling radar for use in climate research. Bull. Amer. Meteor. Soc., 79, 443-455.

Perez, J. C., F. Herrera, F. Rosa, A. Gonzales, M. Wetzel, R. Borys, and D. Lowenthal, 2000: Retrieval of marine stratus cloud droplet size from NOAA AVHRR night imagery. Remote Sens. Environ., 73, 31-45.

Randall, D. A., J. A. Coakley Jr., C. W. Fairall, R. A. Kropfli, and D. H. Lenschow, 1984: Outlook for research on subtropical marine stratiform clouds. Bull. Amer. Meteor. Soc., 65, 1290-1301.

Rosenfeld, D., 2000: Suppression of rain and snow by urban and industrial air pollution. Science, 297, 1793-1796.

Scorer, R. S., 1987: Ship trails. Atmos. Environ., 21, $1417-$ 1425.

Stevens, B., W. R. Cotton, G. Feingold, and C.-H. Moeng, 1998: Large-eddy simulations of strongly precipitating, shallow, stratocumulus-topped boundary layers. J. Atmos. Sci., 55, 3616-3638.

— - and Coauthors, 2003a: On entrainment in nocturnal marine stratocumulus. Quart. J. Roy. Meteor. Soc., 129, 3469-3492.

— Meteor. Soc., 84, 579-593.

Vali, G., R. D. Kelly, J. French, S. Haimov, D. Leon, R. E. McIntosh, and A. Pazmany, 1998: Finescale structure and microphysics of coastal stratus. J. Atmos. Sci., 55, 3540-3564.

van Zanten, M. C., B. Stevens, G. Vali, and D. H. Lenschow, 2004: Observations of drizzle in nocturnal marine stratocumulus. J. Atmos. Sci., 62, 88-106.

Yuter, S. E., Y. L. Serra, and R. A. Houze Jr., 2000: The 1997 Pan American Climate Studies Tropical Eastern Pacific Process Study. Part II: Stratocumulus region. Bull. Amer. Meteor. Soc., 81, 483-490. 